\title{
Research on the Body Injury of Tennis Player's Shot Based on Computer Simulation
}

\author{
Xiaomei Wang ${ }^{1}$, Hongyan $\mathrm{Yu}^{1}$, Chuan $\mathrm{Jin}^{2}$ \\ ${ }^{1}$ Department of Physical Education, Hebei University of Technology, TianJin China \\ w_ang_xiaomei@126.com \\ ${ }^{2}$ Department of Physical Education, TianJin Polytechnic University, TianJin, China
}

\begin{abstract}
Keywords: computer simulation; investigation research; coupling equations; damage mechanism;cumulative damage
\end{abstract}

\begin{abstract}
Through the investigation of tennis player movement and injured basic characteristics in tennis ball shot, analyzes the reason of causing bodily harm includes nodulation sprains, muscle strain, shoulder injuries, ligament damage and fatigue damage. And tennis sports and sports injuries for coupling simulation through the computer, it is concludes that tennis athlete's sports injury and time variation curve. According to the strain curve analyzes that the harm forms larger cumulative damage to human body. At the same time it put forward actively prevent measures on the basis of reasons which leads tennis sports injury .By improving tennis technical action and preparative work, to enhance the tennis players' physical and psychological quality and movement method, so as to reduce the damage degree on tennis team body.
\end{abstract}

\section{Introduction}

Tennis sports belong to a relatively complex technology in movement; not only tennis sports enhanced the human body physique, but also had a strong entertainment appreciation, thus tennis sports got the extensive expansion. With the continuous development of tennis, continuously there was someone to join tennis ranks, especially many universities gradually built tennis court, increased tennis sports course, and gradually cultivated tennis sports personnel[1,2]. But the demand on the athletes' physical quality and technology action is higher in tennis sports, in the tennis movement process; it would be driven that the big muscles and small muscles to related sports participation[3]. At the same time, tennis sports was also a asymmetric movement, had been engaged in the tennis games lead to the body produced asymmetric development. Therefore tennis players were easy to receive damage[4]. How effectively and correctly to analyze the injury of the tennis for tennis players, such as the provision of reference for tennis players in tennis training game that is great significance[5-8].

\section{Research objects and research methods}

A. Investigation object

Aiming at the 150 athletes engaged in the tennis sport from the five higher colleges and universities in a province were investigated and analyzed, then statistical data.

\section{B. Research methods}

\begin{tabular}{|c|c|c|c|c|c|}
\hline & \multicolumn{5}{|c|}{ THE BASIC PROFILE FOR TENNIS PLAYER SURVEY $\left(\boldsymbol{X}^{\boldsymbol{X}} \pm \mathrm{s}\right)$} \\
\hline Gender & $\begin{array}{l}\text { The } \\
\text { total }\end{array}$ & Age & Weight(kg) & Height & $\begin{array}{l}\text { Movement } \\
\text { fixed year }\end{array}$ \\
\hline Male & 94 & $\begin{array}{l}22.54 \\
\pm 0.64 \\
\end{array}$ & $\begin{array}{ll}69.35 & \pm \\
3.21 & \\
\end{array}$ & $\begin{array}{r}176.63 \\
+3.28 \\
\end{array}$ & $2.81 \pm 0.52$ \\
\hline Female & 48 & $\begin{array}{l}21.93 \\
+0.55\end{array}$ & $\begin{array}{ll}53.85 & \pm \\
2.42 & \end{array}$ & $\begin{array}{r}164.22 \\
+4.53\end{array}$ & $3.53 \pm 0.33$ \\
\hline
\end{tabular}

(1) Questionnaire method

Issuing a total of 150 questionnaires, included 142 copies of questionnaires recovery, recovery rate reached $94.7 \%$, effective questionnaire for 141 copies ,effective rate was $99 \%$.

(2) Literature method

Collecting and consulting to tennis sports physiology, sports mechanics and related sports medicine such as the literature data, analyzed the common damage and damage mechanism, disease 
causes for tennis player, in view of the causes of damage to proposed the reasonable measures and methods to get prevention.

(3) The mathematical statistics method

Taking advantage of the mathematical statistics theory and method to achieved the data statistics on tennis player damage survey results.

\section{The results of the survey}

\section{The data statistics of damage site}

From Figure 1 and Table 2, it is known that the damage in tennis player shot mainly displayed in joint sprains, muscle strain, shoulder injuries, ligament damage and fatigue damage, etc. Due to the tennis ball need to the whole body movement together, along with the accumulation of the strength and movement time, tennis players' limbs had became the main parts of the damage. There were researchers who concluded after shot in tennis the athletes' physical damage joint damage account for $22.8 \%$ of the all injuries, followed by the elbow injury. In tennis sports process, muscle damage easily caused by rapid movement in long time and shot, and joint damage, etc.

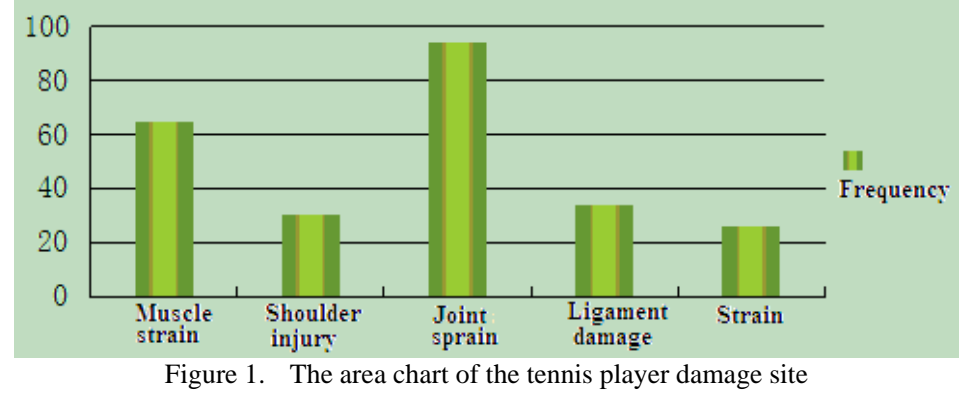

At the same time, the tennis ball movement process, because of a lot of movement required energy supply to cooperate with athlete's rapid movement. Therefore in athletic process, the flow of blood velocity to the organization provided energy supply for limbs and muscle was also influential, through the statistical analysis of the relationship between the tennis ball damage portions and hitting strength for coupling simulation through computer, it is concluded the coupling equation[9].

$$
Q(x)=a(1+m v) e^{m t}+b(1-m v) e^{-m t}-\frac{\delta}{T+Z_{c}}
$$

In which, $Q(x)$ said damage degree quantity; $v$ said tennis hitting power; $m$ said tennis players

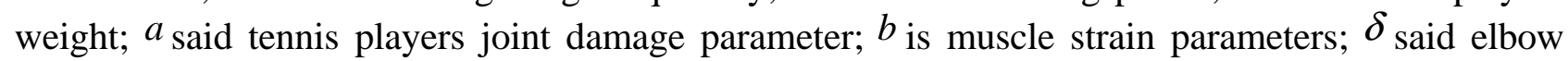
injury degree; $T$ said tennis sports time. $Z_{c}$ said the tennis player cumulative damage coefficient. C. Coupling analysis

According to the above coupling formula and tennis player damage proportion from survey got that the damage coupling model analysis in the tennis athletes shot.

TABLE III. THE TENNIS SPORTS INJURIES COUPLED DATA SHEET
\begin{tabular}{|l|c|c|c|c|c|c|}
\hline & $a$ & $b$ & $\delta$ & $\boldsymbol{v}$ & $\delta$ & $Z_{c}$ \\
\hline 1 & 3.17 & 1.537 & 0.362 & 4.36 & 0.843 & 0.642 \\
\hline 2 & 2.22 & 0.637 & 0.525 & 2.53 & 0.674 & 0.236 \\
\hline 3 & 3.03 & 0.823 & 0.742 & 5.26 & 0.835 & 0.632 \\
\hline 4 & 2.94 & 0.742 & 0.846 & 4.42 & 0.636 & 0.576 \\
\hline 5 & 3.44 & 0.526 & 0.573 & 3.52 & 0.894 & 0.755 \\
\hline Average & 2.96 & 0.853 & 0.6096 & 3.9175 & 0.7764 & 0.5682 \\
\hline
\end{tabular}


In Table 3, the ball sports injuries coupled data shows that numerical average of $a$ said 2.96, $b$ said $0.853, \delta_{\text {said0.6096, }} v$ said3.9175, $\delta_{\text {said } 0.7764 \text { and }} Z_{c}$ said0.5682. . Through the computer coupling simulation, combined with dynamic damage mechanism and the related formula on cumulative damage, get the computation formula about tennis ball bring damage on tennis player is as follows[10-11].

$$
Q_{i n}(x)=\left\{\begin{array}{l}
\frac{2 S V}{T_{S} \cdot T_{P}} t\left(0 \leq t<T_{P}\right) \\
\frac{2 S V}{T_{S}\left(T_{P}-T_{s}\right)}\left(t-T_{p}\right)\left(T_{P} \leq t<T_{s}\right) \\
0\left(T_{s} \leq t<T\right)
\end{array}\right.
$$

Along with time flows, tennis athlete's sports injury change as shown in Figure. The change contrast diagram of coupling curve in Figure 2, it is known that the five curves respectively said joint sprains, muscle strain, shoulder injuries, ligament damage and fatigue damage curve, in which strain finally to form cumulative damage in the harm of human body, the harm of human body is larger. Due to the tennis ball shot need large power, required that the tennis could be quickly reinforce strength, which means that the joint and muscle had a lot of damage, as shown in the curve1 and Curve2 of Figure 2.

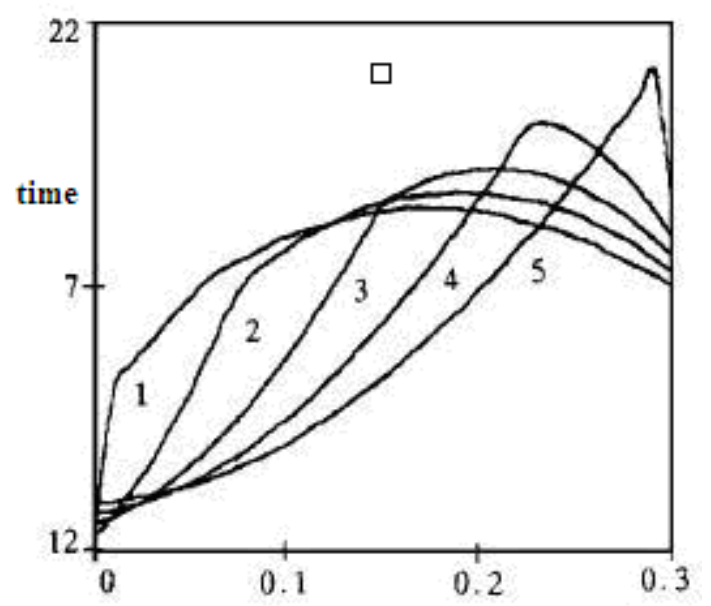

Figure 2. The change contrast diagram of tennis sports injury coupling curve

All of these reflected the process of tennis sports, the harm of tennis ball shot for human body is great, in which mainly the more serious is joint and muscle damage[12,13]. At the same time, along with the accumulation of movement time, tennis players' body formed a cumulative damage; the cumulative damage would be the permanent damage for athletes.

\section{The analysis on tennis sports injury reason}

Through the investigation and the computer simulation analysis, the harm of tennis sports shot for tennis players' body is large; the produced harm also had various reasons. According to the survey results mainly displayed the following aspects: the athletes' physical and mental quality, preparative activities, movement time and local cumulative injury, etc. Statistical results see as Table 4.

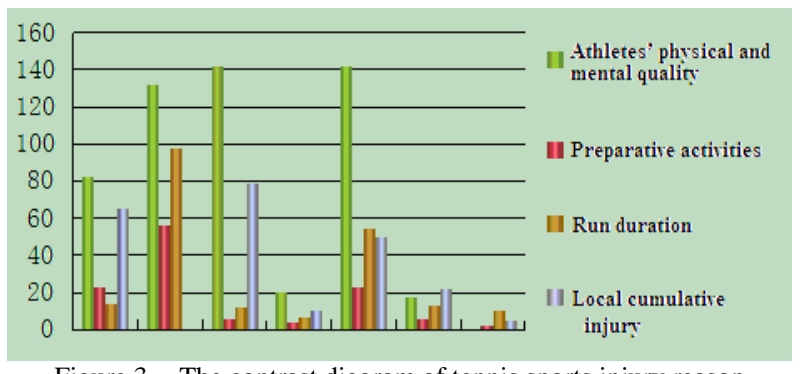

Figure 3. The contrast diagram of tennis sports injury reason 
Table 4 and Figure 3, it is known that the damage reason mainly has the following several aspects[14-16]:

(1) Athletes' physical and mental quality is poor

The athletes' physical quality closely connected to the tennis sports injury. If the athletes' physical quality was not good enough, ligament flexibility difference and power was not enough in tennis movement process, it would be vulnerable. In addition, the athletes' psychological factor was also quite relevant, if athletes' psychological state wasn't ideal, in athletic process for some mistakes or reasons what caused the heart contrast, also appeared that informal shot action, which caused damage.

(2) Preparative activities aren't enough

Because of the tennis sport is one of the extremely intense sports, the basis and premise on whether preparative activities were sufficient or not for athletes' body protection before the sports. If the warming-up before tennis sports was not enough, the athletes' body hadn't fully developed, limb joints and muscle in stiff state, in this kind circumstance exercise would easily cause joint damage and muscle strain.

(3) Movement time and local cumulative injury

As a result of the tennis sports need to repeat practices, if practice time of the hard hit action longer, frequency was too much, the athletes' physical local joint and muscle produced overload operation, could cause acute muscle strain or fracture, and even damage tendons and joint strain fracture. Therefore, tennis sports needed appropriate intermediate rest, provided a recovery time to the improvement of joints, muscles and so on , which was prejudice to form strain.

\section{Conclusion}

For survey analysis through the tennis player shot to body harm, the tennis athletes' physical damage mainly manifests in the joint parts and muscle sprain and strain, and the main reasons for the damage doesn't take motion and technical action in the right mode. Therefore, we need to strengthen the teaching on action technical essentials, the physical and mental exercise. For this purpose, put forward some measures to improve prevention about the tennis sports injury or provide references: (1) it needs to full preparative activities before movement, don't hurry in ready for the body areas , but also needs to make full preparation in the psychology, improves muscle movement ability, which stir up function activities of each joint organ . (2) Mastering correct technical main point of tennis ball shot; (3) Reinforcing their consciousness of protecting movement, to reduce the damage probability of occurrence; (4) Improving the physical quality level, and actively strengthen the strength, speed, endurance and flexibility training, enhance physical quality, to prevent sports injury.

\section{References}

[1] ZhuZhengYu,TanDongPing,ChenQi. The research on the facing bottleneck problem on the development of competitive tennis in China[J].Journal of Guangzhou sports university,2010(5): 1314

[2] LiuHui. The human body joint angle calculation method in the analysis of 3D photography (video)[J]. Beijing sports university Journal,2012 (6): 67-69

[3] ZhangLin. The biomechanics in Sports[M]. Beijing: people's sports press, 2009:498-501

[4] Xuguodong.The Sports medicine and science manual-tennis[M]. People's sports press, 2008:315-317.

[5] LiuWenJuan. The world first-class tennis technology[M]. Beijing sports university press, 2007: 235- 239.

[6] ZhangXiaojun. Discussion on our country outstanding strength training on female tennis players[D]. Beijing sports university,2011.

[7] YanBotao. The biological mechanics analysis on tennis serving technology [J].Journal of sports science, 2010,7 (4): 80-85

[8] LiuHui. The principle of sports biomechanics of tennis serving technology[J]. Beijing sports university journal, 2010(2): 173-176 
[9] Chen Wei. The research on sports specialized students' sports injury[J]. Sports world academic 2010(7):22-25.

[10] LuanLiXia, XuXiangFeng. The research on college tennis sports injury[J]. Wuhan sports university journal, 2011(6):78-81.

[11] TaoQuan. Popular tennis damage causes and prevention research[J]. Jilin sports college journal, 2009(6):87-89.

[12] DaiQingHua, XueTianQing. The discussion on preventing tennis sports injury in representation training method[J]. Weifang education academic journal, 2009(3):45-48.

[13] HanJi, WangLeHua. The condition analysis about our country modern tennis sports injury research[J]. Nanjing sports college journal,2009(9):35-37

[14] TaoQuan. The reasons of the occurrence and prevention countermeasures on tennis rotator cuff injury [J]. Nanjing sports college journal(natural science edition), 2006(3): 71-73.

[15] SongZhiLiang. The common injury, treatment and prevention in our school college tennis sports[J]. Qiqihar university journal (philosophy and social science edition), 2009 (9) : 174-175.

[16] LuanLiXia, XuXiangFeng. The research on college tennis sports injury[J]. Wuhan sports university journal, 2011 (6): 92-95.

TABLE II. THE DATA STATISTICS OF TENNIS PLAYER DAMAGE SITE

\begin{tabular}{|l|l|l|l|l|l|l|l|l|l|}
\hline \multirow{2}{*}{$\begin{array}{c}\text { Damage } \\
\text { type }\end{array}$} & \multirow{2}{*}{$\begin{array}{c}\text { Frequ } \\
\text { ency }\end{array}$} & \multicolumn{9}{|c|}{ Injuries portion } \\
\cline { 3 - 10 }$y$ & Back & Shoulder & Ankle & Waist & Knee & Thigh & Calf & Cubits \\
\hline Muscle & 65 & 21 & 0 & 0 & 5 & 0 & 14 & 17 & 7 \\
\hline Shoulder & 30 & 0 & 30 & 0 & 0 & 0 & 0 & 0 & 0 \\
\hline Joint & 94 & 0 & 22 & 42 & 0 & 0 & 0 & 30 & 0 \\
\hline Ligament & 34 & 0 & 0 & 0 & 0 & 0 & 23 & 11 & 0 \\
\hline Strain & 26 & 0 & 0 & 0 & 11 & 15 & 0 & 0 & 0 \\
\hline Total & 244 & 21 & 53 & 42 & 16 & 15 & 37 & 58 & 7 \\
\hline$\%$ & & 9.3 & 20.7 & 15.2 & 8.3 & 7.5 & 14.3 & 22.8 & 3.3 \\
\hline
\end{tabular}

TABLE IV. THE SURVEY STATISTICS CHART OF TENNIS SPORTS INJURY REASON

\begin{tabular}{|l|l|l|l|l|l|l|l|l|l|}
\hline \multicolumn{1}{|c|}{ Injury parts and reason } & Wrist & Shoulder & Cubits & Leg & Ankle & Knee & Back & Total & \multicolumn{1}{c|}{ \% } \\
\hline Athletes' physical and mental quality & 82 & 132 & 142 & 20 & 142 & 17 & -- & 642 & 53.3 \\
\hline Preparative activities & 23 & 56 & 6 & 4 & 23 & 6 & 2 & 103 & 9.6 \\
\hline Run duration & 14 & 98 & 12 & 7 & 54 & 13 & 10 & 191 & 15.9 \\
\hline Local cumulative injury & 65 & -- & 79 & 10 & 50 & 22 & 5 & 241 & 21.8 \\
\hline Total & 186 & 328 & 292 & 36 & 273 & 48 & 17 & -- & -- \\
\hline Percentage \% & 12.2 & 28.9 & 22.1 & 4.0 & 25.1 & 4.3 & 1.6 & -- & -- \\
\hline
\end{tabular}

